\title{
EMERGENCE OF TAPERED DUCTS IN VASCULAR DESIGNS WITH LAMINAR AND TURBULENT FLOWS
}

\author{
Erdal Cetkin
}

\author{
Izmir Institute of Technology, Department of Mechanical Engineering, Urla, Izmir 35430, Turkey; \\ E-mail:erdalcetkin@iyte.edu.tr
}

Original Manuscript Submitted: 2/4/2014; Final Draft Received: 3/4/2014

\begin{abstract}
Here we show that tapered ducts emerge in volumetrically bathed porous materials to decrease the resistance to the flow in laminar and turbulent flow regimes. The fluid enters the volume from one point and it is distributed to the entire volume. After bathing the volume, it is collected and leaves the volume from another point, i.e., two trees matched canopy to canopy. This paper shows that the flow architecture (i.e., design of the void spaces in a porous material) should be changed to obtain the minimum resistance to the flow as its size increases. Tapering the ducts decreases the order of the transition size, i.e., the size for changing from one construct to another to obtain the minimum pressure drop. The decrease in the pressure drop is $16 \%$ and $38 \%$ with the tapered ducts when the flow is laminar and turbulent, respectively. In addition, the volume ratios and the shape of the tapered ducts are documented. There is no design existing in nature with diameters of constant size in order to distribute and/or collect heat, fluid, and/or stress such as bones, rivers, veins, and tree branches. The emergence of the tapered ducts in designed porous materials is natural.
\end{abstract}

KEY WORDS: constructal law, designed porosity, vascular, tapered, laminar, turbulent, dendritic

\section{INTRODUCTION}

Advanced technologies require designing porous materials by embedding vascular flow channels in them to gain smart capabilities such as self-healing and self-cooling (Aragon et al., 2013; Bejan et al., 2006; Cetkin et al., 2011; Hamilton et al., 2010; Lorente and Bejan, 2009; Therriault et al., 2003; Soghrati et al., 2012). These smart capabilities are the result of the ability of the porous materials to bathe their entire body volumetrically. In the current literature, vascular structures with designed porosity consist of ducts of constant diameters embedded in them to bathe its volume with a fluid (Cetkin et al., 2010; Chen and Cheng, 2005; Cho et al., 2011; Errera and Bejan, 1999; Kim et al., 2008; Liu and Li, 2013; Miguel, 2010a,b). However, no constant diameter collecting or distributing system exists in nature. In nature, all the channels are tapered (i.e., finger-shaped) such as tree roots and branches, blood veins, bones, rivers, and even snowflakes independent of what flows along the channel, i.e., fluid, heat, and/or stress (Bejan and
Lorente, 2008; Bejan and Zane, 2012; da Silva and Bejan, 2005).

This tapered design is the result of minimizing the flow resistances along the channel in which heat, fluid, and/or stress flow. This phenomenon of design evolution is described as the constructal law in the literature (Bejan and Lorente, 2008, 2010; Bejan and Zane, 2012; da Silva and Bejan, 2005). Every flow system changes its shape in time to decrease the flow resistances. The current literature also shows that constructal law is valid for the animate (Miguel, 2006; Reis and Miguel, 2006; Reis et al., 2004) and inanimate (Bejan and Lorente, 2013; Beyene and Peffley, 2009; Lorenzini and Rocha, 2009; Raja et al., 2008; Reis, 2006a,b; Rocha et al., 2005; Tondeur and Luo, 2004; Wang et al., 2006; Wechsatol et al., 2006; Wu et al., 2007a,b; Xu et al., 2008; Zhou et al., 2007).

This paper introduces the merit of the tapered ducts in designed porous materials by comparing the pressure drops of the vascular designs with ducts of constant diameter and tapered ducts. The pressure drops in the vascular structures are calculated for laminar and turbulent flows. 


\section{NOMENCLATURE}

$\mathrm{C}_{1} \quad$ factor for laminar flow, $\mathrm{m}^{2} / \mathrm{s}$, Eq. (1)

$\mathrm{C}_{\mathrm{t}} \quad$ factor for turbulent flow, $\mathrm{m}^{3} / \mathrm{kg}$, Eq. (2)

d element thickness, m, Fig. 1

D channel diameter, $m$

f constant friction factor for fully rough and fully developed turbulent flow

$\mathrm{H} \quad$ element height, m, Fig. 2

L stack length, m, Figs. 1 and 2

$\dot{\mathrm{m}}$ mass flow rate, $\mathrm{kg} / \mathrm{s}$

$\mathrm{n}$ number of elements

p number of pieces, Fig. 3

$r \quad$ number of pieces, Fig. 5

$\mathrm{V}$ flow volume, $\mathrm{m}^{3}$

$\mathrm{V}_{s} \quad$ solid volume, $\mathrm{m}^{3}$

$\mathrm{x}$ the distance from the closed end of the duct, m, Fig. 1 y element width, m, Fig. 1

\section{Greek Symbols}

$\Delta \mathrm{P}$ pressure difference, $\mathrm{Pa}$

$v \quad$ kinematic viscosity, $\mathrm{m}^{2} / \mathrm{s}$

$\rho$ density, $\mathrm{kg} / \mathrm{m}^{3}$

$\phi$ porosity

\section{Subscripts}

cons constant

e element

i rank of construct

1 laminar

min minimum

$\mathrm{t}$ turbulent

var variable

\section{DISTRIBUTION DUCT}

Consider a duct which discharge fluid along its length, Fig. 1. This duct is connected to a number of elemental volumes receiving the fluid along its length. The flow rate in the duct varies linearly, $\dot{\mathrm{m}}(\mathrm{x})=\dot{\mathrm{m} x} / \mathrm{L}$. The pressure drops for laminar and turbulent flows are

$$
\Delta \mathrm{P}_{1}=\mathrm{C}_{1} \frac{\dot{\mathrm{m}}}{\mathrm{L}} \int_{0}^{\mathrm{L}} \frac{\mathrm{x}}{\mathrm{D}^{4}} \mathrm{dx}
$$
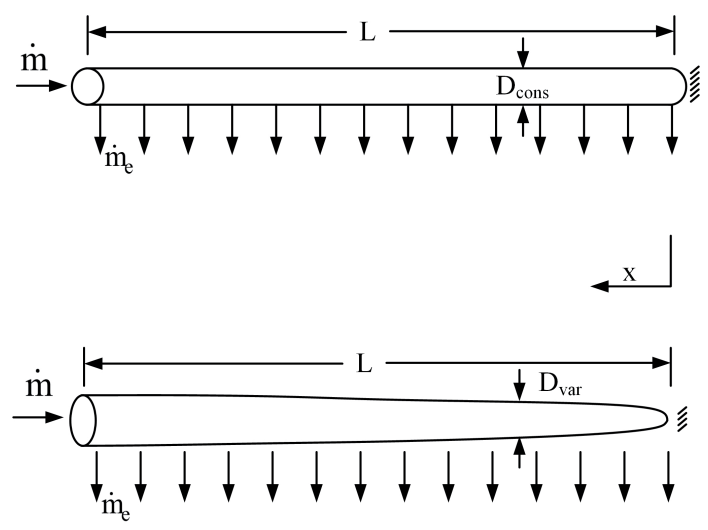

FIG. 1: Duct with longitudinally distributed discharge: tube with constant diameter (top) and tapered tube (bottom)

$$
\Delta \mathrm{P}_{\mathrm{t}}=\mathrm{C}_{\mathrm{t}} \frac{\dot{\mathrm{m}}^{2}}{\mathrm{~L}^{2}} \int_{0}^{\mathrm{L}} \frac{\mathrm{x}^{2}}{\mathrm{D}^{5}} \mathrm{dx}
$$

where $C_{l}=128 / v \pi$ and $C_{t}=32 f / \pi^{2} \rho . \nu, \rho$, and $f$ are the kinematic viscosity and the density of the fluid and the constant friction factor for turbulent flow in the fully developed and fully rough regime, respectively (Bejan and Lorente, 2008). $\dot{\mathrm{m}}, \mathrm{L}, \mathrm{x}$, and D are the mass flow rate that enters the duct, the length, the distance from the closed end of the duct, and the diameter, respectively. The subscript of 1 and $t$ represents laminar and turbulent flows, respectively.

The volume constraint is

$$
\mathrm{V}=\int_{0}^{\mathrm{L}} \frac{\pi}{4} \mathrm{D}^{2} \mathrm{dx}
$$

The pressure drops for laminar and turbulent flow regimes along the duct with constant diameter are

$$
\begin{aligned}
\Delta \mathrm{P}_{0,1} & =\mathrm{C}_{1} \frac{\dot{\mathrm{m} L}}{2 \mathrm{D}_{\text {cons }}^{4}} \\
\Delta \mathrm{P}_{0, \mathrm{t}} & =\mathrm{C}_{\mathrm{t}} \frac{\dot{\mathrm{m}}^{2} \mathrm{~L}}{3 \mathrm{D}_{\text {cons }}^{5}}
\end{aligned}
$$

Now consider the duct shape is free to vary. By using variational calculus, Eqs. (1) and (2) can be minimized subject to the volume constraint of Eq. (3). The diameters 
of the tapered ducts and the pressure drop corresponding to the tapered ducts for laminar and turbulent flows are

$$
\begin{gathered}
\mathrm{D}_{\text {var }, \mathrm{l}}=\left(\frac{16}{3 \pi} \frac{\mathrm{V}}{\mathrm{L}}\right)^{1 / 2}\left(\frac{\mathrm{x}}{\mathrm{L}}\right)^{1 / 6} \\
\Delta \mathrm{P}_{\min , \mathrm{l}}=\frac{3^{3} \pi^{2}}{4^{5}} \frac{\mathrm{C}_{\mathrm{l}} \dot{\mathrm{L}}^{3}}{\mathrm{~V}^{2}} \\
\mathrm{D}_{\mathrm{var}, \mathrm{t}}=\left(\frac{44}{7 \pi} \frac{\mathrm{V}}{\mathrm{L}}\right)^{1 / 2}\left(\frac{\mathrm{x}}{\mathrm{L}}\right)^{2 / 7} \\
\Delta \mathrm{P}_{\min , \mathrm{t}}=\mathrm{C}_{\mathrm{t}} \dot{\mathrm{m}}^{2}\left(\frac{7}{11}\right)^{7 / 2}\left(\frac{\pi}{4}\right)^{5 / 2} \frac{\mathrm{L}^{7 / 2}}{\mathrm{~V}^{5 / 2}}
\end{gathered}
$$

Dividing Eqs. (7) and (9) by Eqs. (4) and (5), respectively, shows the reduction in the flow resistance by tapering the ducts in laminar and turbulent flows

$$
\begin{gathered}
\frac{\Delta \mathrm{P}_{\min , \mathrm{l}}}{\Delta \mathrm{P}_{0,1}}=\frac{3^{3} 2}{4^{3}}=0.84 \\
\frac{\Delta \mathrm{P}_{\min , \mathrm{t}}}{\Delta \mathrm{P}_{0, \mathrm{t}}}=3\left(\frac{7}{11}\right)^{7 / 2}=0.62
\end{gathered}
$$

The results of Eqs. (10) and (11) show that the flow resistance of the tapered ducts is smaller when the duct discharges fluid along its length. In the laminar flow regime, modeling the channel as a constant diameter duct would not affect the results as much as it does in turbulent flow.

\section{FIRST CONSTRUCT}

Consider now the stack of $\mathrm{n}$ number of elemental volumes, Fig. 2. The stream $\dot{m}$ is distributed to the elemental volumes along the discharge duct. Then it is collected from the elemental volumes with the collecting duct. The porous material gains smart capabilities with the distributed and collected stream of coolant and/or healing agent throughout the solid volume. The solid material is removed in order to create distributing and collecting ducts shown in Fig. 2. The porosity of the vascular structure is the ratio of the solid volume divided by the created void volume for fluid to flow, i.e., $\phi=\mathrm{V}_{s} / \mathrm{V}$. The solid volume throughout the paper is fixed, and it is $\mathrm{L} \times \mathrm{H} \times \mathrm{y}$.

The stream is distributed and collected by two horizontal channels (diameter $\mathrm{D}_{1}$ ), one along the top and the other along the bottom. The stack of $n$ elements of size $\mathrm{d} \times \mathrm{H} \times \mathrm{y}$ fills a volume of length $\mathrm{L}=\mathrm{nd}$, height $\mathrm{H}$, and thickness y, which is perpendicular to the plane of Fig. 2. The pressure drop from one end of the elemental volume to the other is fixed. The flow rate $\dot{m}$ is steady and known.

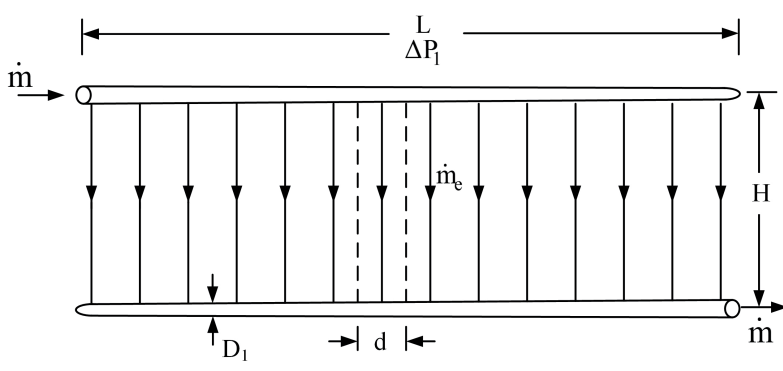

FIG. 2: Stack of $n$ elemental volumes bathed by a single stream

The pressure drop along the supply duct of Fig. 2 is the expression of Eqs. (7) and (9) in tapered ducts for laminar and turbulent flows, respectively.

\section{SECOND CONSTRUCT}

Consider next the question of whether it is beneficial to configure the stack in a way which is different than in Fig. 2. A two-dimensional alternative is shown in Fig. 3, which is the result of cutting the stack of Fig. 2 into $p$



FIG. 3: Stack of $p$ elemental volumes of size $L / p$ 
equal pieces, and stacking these pieces in the vertical direction. This new design has a two-dimensional pattern with the vertical dimension $\mathrm{pH}$ and the horizontal dimension $\mathrm{L} / \mathrm{p}$. The flow is distributed by $\mathrm{p}$ horizontal channels of length $L / p$ and diameter $D_{1}$ and a vertical channel of height $(\mathrm{p}-1) \mathrm{H}$ and diameter $\mathrm{D}_{2}$.

To compare Figs. 1 and 3 analytically and on the same basis, we assume that the configuration and flow needs of a single $\mathrm{d} \times \mathrm{H} \times \mathrm{y}$ element are fixed. This means that $\mathrm{H}$, $\mathrm{d}, \dot{\mathrm{m}}_{\mathrm{e}}=\dot{m} / \mathrm{n}$, and the diameter of the thin channel that runs along the centerline of the element is fixed. Therefore, the pressure drop $\Delta \mathrm{P}_{e}$ from one end of the $\mathrm{d} \times \mathrm{H} \times \mathrm{y}$ element to the other end is fixed.

The pressure drop for a channel with laminar and turbulent flows are as in Eqs. (4) and (5) with constant diameter and as in Eqs. (7) and (9) with tapered ducts. The pressure drop along the distributing ducts in Fig. 3 has two parts: the pressure drop along one duct of diameter $\mathrm{D}_{2}$ and length $(\mathrm{p}-1) \mathrm{H}$ and $\mathrm{p}$ ducts of diameter $\mathrm{D}_{1}$ and length $\mathrm{L} / \mathrm{p}$. The total volume of the distributing ducts are

$$
\mathrm{V}=\mathrm{V}_{2}+p \mathrm{~V}_{1}
$$

The pressure drops along the distributing tapered ducts are

$$
\begin{aligned}
& \Delta \mathrm{P}_{2, \mathrm{l}}=\left(\frac{3}{4}\right)^{3}\left(\frac{\pi}{4}\right)^{2} \mathrm{C}_{\mathrm{l}} \dot{\mathrm{m}} \frac{[(\mathrm{p}-1) \mathrm{H}]^{3}}{\left(\mathrm{~V}_{2}\right)^{2}}+\left(\frac{3}{4}\right)^{3}\left(\frac{\pi}{4}\right)^{2} \\
& \times \mathrm{C}_{1} \frac{\dot{\mathrm{m}}}{\mathrm{p}} \frac{(\mathrm{L} / p)^{3}}{\left(\mathrm{~V}_{1}\right)^{2}} \\
& \Delta \mathrm{P}_{2, \mathrm{t}}=\left(\frac{7}{11}\right)^{7 / 2}\left(\frac{\pi}{4}\right)^{5 / 2} \mathrm{C}_{\mathrm{t}} \dot{\mathrm{m}}^{2} \frac{[(\mathrm{p}-1) \mathrm{H}]^{7 / 2}}{\left(\mathrm{~V}_{2}\right)^{5 / 2}} \\
& +\left(\frac{7}{11}\right)^{7 / 2}\left(\frac{\pi}{4}\right)^{5 / 2} \mathrm{C}_{\mathrm{t}} \frac{\dot{\mathrm{m}}^{2}}{\mathrm{p}^{2}} \frac{(\mathrm{L} / \mathrm{p})^{7 / 2}}{\left(\mathrm{~V}_{1}\right)^{5 / 2}}
\end{aligned}
$$

where the diameters of the ducts vary as in Eqs. (6) and (8),

$$
\begin{aligned}
\mathrm{D}_{\mathrm{i}, \mathrm{l}} & =\left(\frac{16}{3 \pi} \frac{\mathrm{V}_{\mathrm{i}}}{\mathrm{L}_{\mathrm{i}}}\right)^{1 / 2}\left(\frac{\mathrm{x}}{\mathrm{L}_{\mathrm{i}}}\right)^{1 / 6} \\
\mathrm{D}_{\mathrm{i}, \mathrm{t}} & =\left(\frac{44}{7 \pi} \frac{\mathrm{V}_{\mathrm{i}}}{\mathrm{L}_{\mathrm{i}}}\right)^{1 / 2}\left(\frac{\mathrm{x}}{\mathrm{L}_{\mathrm{i}}}\right)^{2 / 7}
\end{aligned}
$$

where $\mathrm{L}_{1}=\mathrm{L} / p$ and $\mathrm{L}_{2}=(\mathrm{p}-1) \mathrm{H}$. The flow rate through the $\mathrm{D}_{1}$ duct is $\dot{\mathrm{m}} / \mathrm{p}$, and it appears as $\dot{\mathrm{m}}^{2} / \mathrm{p}^{2}$ in Eq. (14) because in turbulent flow the pressure drop is proportional to $\dot{\mathrm{m}}^{2}$.
The total space occupied by the first and second constructs (Figs. 1 and 3$)$ is the same, $(\mathrm{pH}) \times(\mathrm{L} / \mathrm{p})=\mathrm{LH}$. The only degree of freedom in the minimization of the pressure drop is the ratio of $V_{2} / V_{1}$. By minimizing $\Delta P_{2}$ with respect to the $V_{2} / V_{1}$ subject to constraint of Eq. (12), we find

$$
\begin{aligned}
& \left(\frac{\mathrm{V}_{2}}{\mathrm{~V}_{1}}\right)_{1}=\mathrm{p}^{2 / 3} \frac{(\mathrm{p}-1) \mathrm{H}}{\mathrm{L} / \mathrm{p}} \\
& \left(\frac{\mathrm{V}_{2}}{\mathrm{~V}_{1}}\right)_{\mathrm{t}}=\mathrm{p}^{6 / 7} \frac{(\mathrm{p}-1) \mathrm{H}}{\mathrm{L} / \mathrm{p}}
\end{aligned}
$$

The minimized pressure drops are

$$
\begin{aligned}
\Delta \mathrm{P}_{2, \mathrm{l}} & =\left(\frac{3}{4}\right)^{3}\left(\frac{\pi}{4}\right)^{2} \mathrm{C}_{\mathrm{l}} \frac{\dot{\mathrm{m}} \mathrm{L}^{3}}{\mathrm{p}^{2} \mathrm{~V}^{2}}\left[\frac{\mathrm{H}}{\mathrm{L}}(\mathrm{p}-1) \mathrm{p}^{2 / 3}+1\right]^{3} \\
& \Delta \mathrm{P}_{2, \mathrm{t}}=\left(\frac{7}{11}\right)^{7 / 2}\left(\frac{\pi}{4}\right)^{5 / 2} \mathrm{C}_{\mathrm{t}} \frac{\dot{\mathrm{m}}^{2} \mathrm{~L}^{7 / 2}}{\mathrm{p}^{3} \mathrm{~V}^{5 / 2}} \\
& \times\left[\frac{\mathrm{H}}{\mathrm{L}}(\mathrm{p}-1) \mathrm{p}^{6 / 7}+1\right]^{7 / 2}
\end{aligned}
$$

The minimized pressure drops for the constant diameter ducts are (Kim et al., 2008; Cetkin et al., 2010)

$$
\begin{gathered}
\Delta \mathrm{P}_{2,1, \mathrm{D}=\text { const }}=\left(\frac{1}{2}\right)\left(\frac{\pi}{4}\right)^{2} \mathrm{C}_{\mathrm{l}} \frac{\dot{\mathrm{m}} \mathrm{L}^{3}}{\mathrm{p}^{2} \mathrm{~V}^{2}} \\
\times\left[\frac{\mathrm{H}}{\mathrm{L}}(\mathrm{p}-1) \mathrm{p}^{2 / 3}+1\right]^{3} \\
\Delta \mathrm{P}_{2, \mathrm{t}, \mathrm{D}=\text { const }}=\left(\frac{1}{3}\right)\left(\frac{\pi}{4}\right)^{5 / 2} \mathrm{C}_{\mathrm{t}} \frac{\dot{\mathrm{m}}^{2} \mathrm{~L}^{7 / 2}}{\mathrm{p}^{3} \mathrm{~V}^{5 / 2}} \\
\times\left[\frac{\mathrm{H}}{\mathrm{L}}(\mathrm{p}-1) \mathrm{p}^{6 / 7}+1\right]^{7 / 2}
\end{gathered}
$$

Dividing Eq. (19) by Eq. (21) and Eq. (20) by Eq. (22), we discover the merit of the tapered ducts,

$$
\begin{aligned}
& \frac{\Delta \mathrm{P}_{2,1}}{\Delta \mathrm{P}_{2, \mathrm{l}, \mathrm{D}=\text { const }}}=0.84 \\
& \frac{\Delta \mathrm{P}_{2, \mathrm{t}}}{\Delta \mathrm{P}_{2, \mathrm{t}, \mathrm{D}=\text { const }}}=0.62
\end{aligned}
$$

These ratios are the same as in Eqs. (10) and (11). The gain in the pressure drop by introducing the tapered ducts is a constant for the second construct as in the first construct. Tapering the ducts decreases the pressure drop by $16 \%$ and $38 \%$ for laminar and turbulent flows, respectively. 
Figure 4 shows the pressure drop of the second construct relative to the size of the construct (nd/y) in laminar (top) and turbulent (bottom) flows. The pressure drop can be decreased by increasing $\mathrm{p}$ as nd/y increases. The pressure drop of the second construct decreases when the ducts are tapered. The nd/y ratio for increasing $p$ to obtain the minimum pressure drop also decreases with the tapered ducts, Fig. 4.
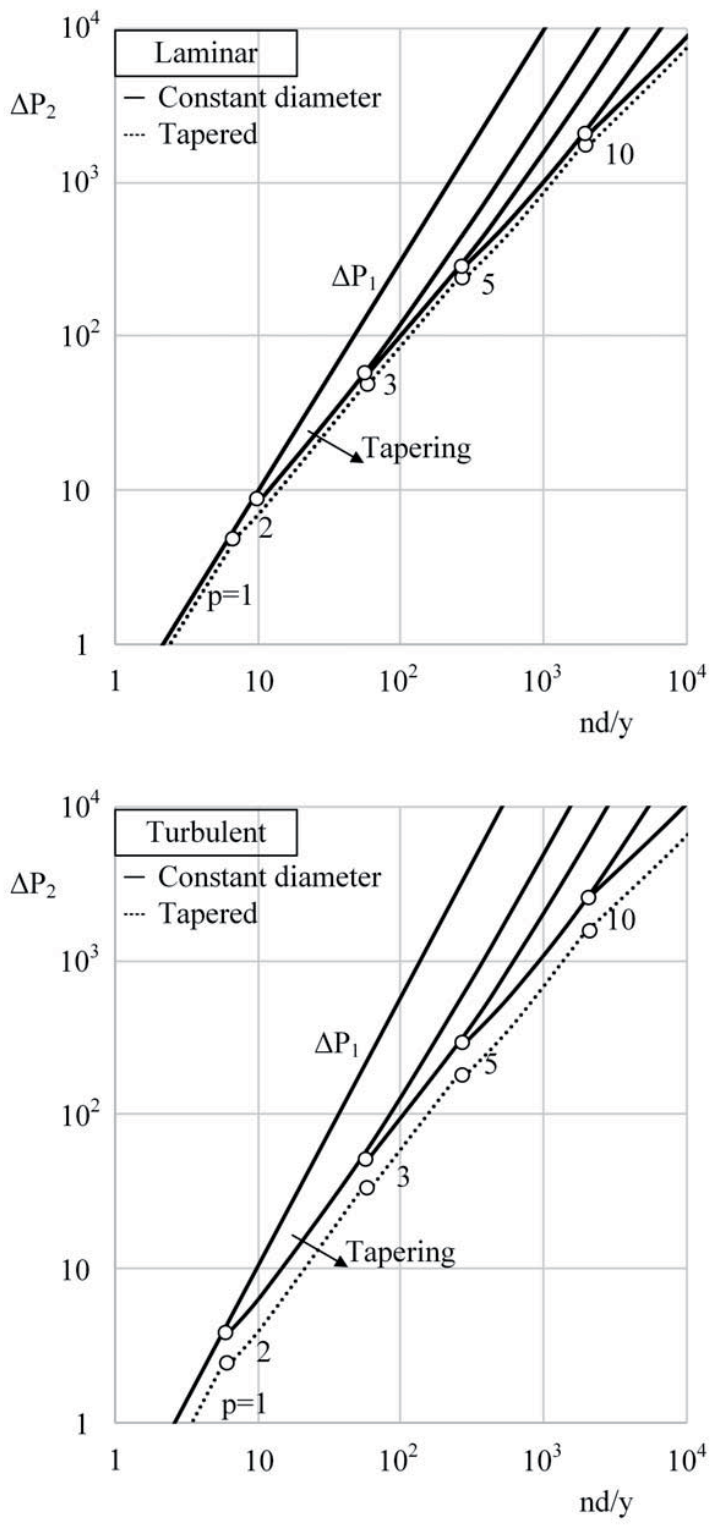

FIG. 4: The flow performance of the second construct of Fig. 3

\section{THIRD CONSTRUCT}

Stacking the second construct in three-dimensional orientation [Fig. 5 (top)] and cutting it into $r$ equal pieces, and then stacking the equal pieces in the direction perpendicular to the $\mathrm{D}_{2}-\mathrm{D}_{1}$ plane, we obtain a new architecture, Fig. 5 (bottom). The size of this new design is $(\mathrm{rH}) \times(\mathrm{py} / \mathrm{r}) \times(\mathrm{L} / \mathrm{p})=\mathrm{LHy}$. The volume occupied by this construct is same as in the first and second constructs.

The stream enters this body through one duct of diameter $\mathrm{D}_{3}$ and length $(\mathrm{r}-1) \mathrm{H}$. Then it is distributed from the $\mathrm{D}_{3}$ duct to the $\mathrm{D}_{2}$ ducts, after which it follows the same path as in the second construct, Fig. 3. The pressure drop across the third construct consists of three terms for tapered ducts in laminar and turbulent flows, respectively.

$$
\begin{aligned}
& \Delta \mathrm{P}_{3, \mathrm{l}}=\left(\frac{3}{4}\right)^{3}\left(\frac{\pi}{4}\right)^{2}\left[\mathrm{C}_{1} \dot{\mathrm{m}} \frac{[(r-1) \mathrm{H}]^{3}}{\mathrm{~V}_{3}^{2}}+\mathrm{C}_{1} \frac{\dot{\mathrm{m}}}{r} \frac{[\mathrm{p} y / r]^{3}}{\mathrm{~V}_{2}^{2}}\right. \\
& \left.+\mathrm{C}_{1} \frac{\dot{\mathrm{m}}}{\mathrm{p}} \frac{[\mathrm{L} / \mathrm{p}]^{3}}{\mathrm{~V}_{1}^{2}}\right]
\end{aligned}
$$

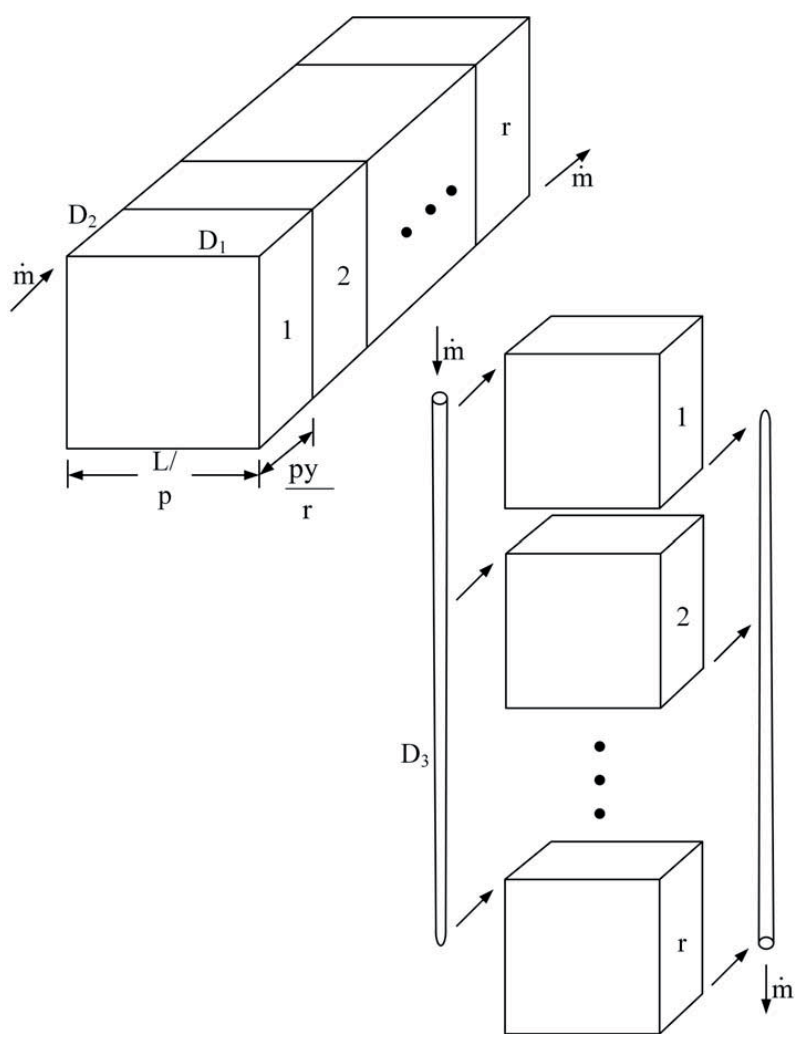

FIG. 5: Third construct: the $r$ segments are stacked in the direction perpendicular to the $\mathrm{D}_{2}-\mathrm{D}_{1}$ plane 


$$
\begin{aligned}
& \Delta \mathrm{P}_{3, \mathrm{t}}=\left(\frac{7}{11}\right)^{7 / 2}\left(\frac{\pi}{4}\right)^{5 / 2}\left[\mathrm{C}_{\mathrm{t}} \dot{\mathrm{m}}^{2} \frac{[(r-1) \mathrm{H}]^{7 / 2}}{\mathrm{~V}_{3}^{5 / 2}}\right. \\
& \left.+\mathrm{C}_{\mathrm{t}} \frac{\dot{\mathrm{m}}^{2}}{r^{2}} \frac{[p y / r]^{7 / 2}}{\mathrm{~V}_{2}^{5 / 2}}+\mathrm{C}_{\mathrm{t}} \frac{\dot{\mathrm{m}}^{2}}{\mathrm{p}^{2}} \frac{[\mathrm{L} / \mathrm{p}]^{7 / 2}}{\mathrm{~V}_{1}^{5 / 2}}\right]
\end{aligned}
$$

The total volume of the distribution ducts is

$$
\mathrm{V}=\mathrm{V}_{3}+r \mathrm{~V}_{2}+p \mathrm{~V}_{1}
$$

The diameter of the ducts vary as in Eqs. (15) and (16), where $\mathrm{L}_{1}=\mathrm{L} / \mathrm{p}, \mathrm{L}_{2}=$ py $/ \mathrm{r}$, and $\mathrm{L}_{3}=(r-1) \mathrm{H}$. By minimizing $\Delta \mathrm{P} 3$ with respect to the $\mathrm{V}_{2} / \mathrm{V}_{1}$ and $\mathrm{V}_{3} / \mathrm{V}_{1}$ subject to constraint of Eq. (27), we find

$$
\begin{aligned}
& \left(\frac{\mathrm{V}_{2}}{\mathrm{~V}_{1}}\right)_{l}=\left(\frac{\mathrm{p}}{r}\right)^{2 / 3} \frac{\mathrm{py} / \mathrm{r}}{\mathrm{L} / \mathrm{p}}\left(\frac{\mathrm{V}_{3}}{\mathrm{~V}_{1}}\right)_{l}=\mathrm{p}^{2 / 3} \frac{(r-1) \mathrm{H}}{\mathrm{L} / \mathrm{p}} \\
& \left(\frac{\mathrm{V}_{2}}{\mathrm{~V}_{1}}\right)_{t}=\left(\frac{\mathrm{p}}{r}\right)^{6 / 7} \frac{\mathrm{py} / \mathrm{r}}{\mathrm{L} / \mathrm{p}}\left(\frac{\mathrm{V}_{3}}{\mathrm{~V}_{1}}\right)_{t}=\mathrm{p}^{6 / 7} \frac{(r-1) \mathrm{H}}{\mathrm{L} / \mathrm{p}}
\end{aligned}
$$

The minimized pressure drops of the structures with tapered ducts are

$$
\begin{aligned}
& \Delta \mathrm{P}_{3, \mathrm{l}}=\left(\frac{3}{4}\right)^{3}\left(\frac{\pi}{4}\right)^{2} \mathrm{C}_{1} \frac{\dot{\mathrm{m}} y^{3}}{\mathrm{~V}^{2}}\left[\frac{\mathrm{H}}{y}(r-1)+\mathrm{p}^{-2 / 3}\right. \\
& \left.+\mathrm{p}^{-2 / 3} \frac{n d}{y}\right]^{3} \\
& \Delta \mathrm{P}_{3, \mathrm{t}}=\left(\frac{7}{11}\right)^{7 / 2}\left(\frac{\pi}{4}\right)^{5 / 2} \mathrm{C}_{\mathrm{t}} \frac{\dot{\mathrm{m}}^{2} y^{7 / 2}}{\mathrm{~V}^{5 / 2}}\left[\frac{\mathrm{H}}{y}(r-1)\right. \\
& \left.+\mathrm{p}^{-6 / 7}+\mathrm{p}^{-6 / 7} \frac{n d}{y}\right]^{7 / 2}
\end{aligned}
$$

The minimized pressure drops for the constant diameter ducts are (Kim et al., 2008; Cetkin et al., 2010)

$$
\begin{aligned}
& \Delta \mathrm{P}_{3,1, \mathrm{D}=\text { const }}=\left(\frac{1}{2}\right)\left(\frac{\pi}{4}\right)^{2} \mathrm{C}_{1} \frac{\dot{\mathrm{m}} y^{3}}{\mathrm{~V}^{2}}\left[\frac{\mathrm{H}}{y}(r-1)\right. \\
& \left.+\mathrm{p} r^{-2 / 3}+\mathrm{p}^{-2 / 3} \frac{n d}{y}\right]^{3} \\
& \Delta \mathrm{P}_{3, \mathrm{t}, \mathrm{D}=\text { const }}=\left(\frac{1}{3}\right)\left(\frac{\pi}{4}\right)^{5 / 2} \mathrm{C}_{\mathrm{t}} \frac{\dot{\mathrm{m}}^{2} y^{7 / 2}}{\mathrm{~V}^{5 / 2}} \\
& \times\left[\frac{\mathrm{H}}{y}(r-1)+\mathrm{p}^{-6 / 7}+\mathrm{p}^{-6 / 7} \frac{n d}{y}\right]^{7 / 2}
\end{aligned}
$$

Dividing Eq. (30) by Eq. (32) and Eq. (31) by Eq. (33), we discover the merit of the tapered ducts,

$$
\begin{gathered}
\frac{\Delta \mathrm{P}_{3,1}}{\Delta \mathrm{P}_{3,1, \mathrm{D}=\text { const }}}=0.84 \\
\frac{\Delta \mathrm{P}_{3, \mathrm{t}}}{\Delta \mathrm{P}_{3, \mathrm{t}, \mathrm{D}=\text { const }}}=0.62
\end{gathered}
$$

Similar to the second construct, these ratios of Eqs. (34) and (35) are the same as in Eqs. (10) and (11). Figure 6 shows the merit in the pressure drop relative to nd/y ratio, namely $16 \%$ and $38 \%$ decrease with tapered ducts for laminar and turbulent flows, respectively.
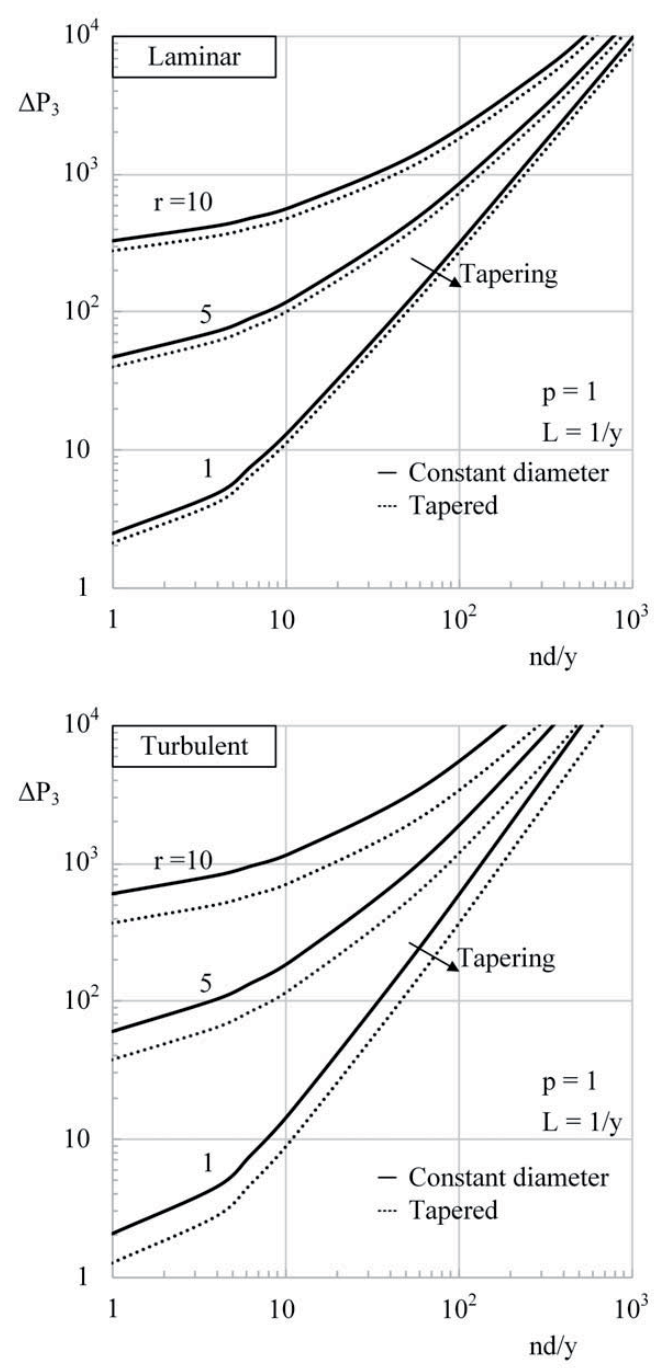

FIG. 6: The performance curves of the designs of Fig. 5 
Figure 7 shows the pressure drops of the first (Fig. 2), second (Fig. 3), and third (Fig. 5) constructs divided by the pressure drop of the first construct (Fig. 2) with laminar and turbulent flows. Figure 7 illustrates that the shape of the construct should be changed to keep the pressure drop in minimum as the size of the construct increases. The nd/y ratio corresponding to the shape change, i.e., transition point from one construct to the other, decreases as the ducts of the construct are tapered, Fig. 7. Tapering shifted the pressure drop by $16 \%$ and $38 \%$ less for laminar and turbulent flows, respectively.
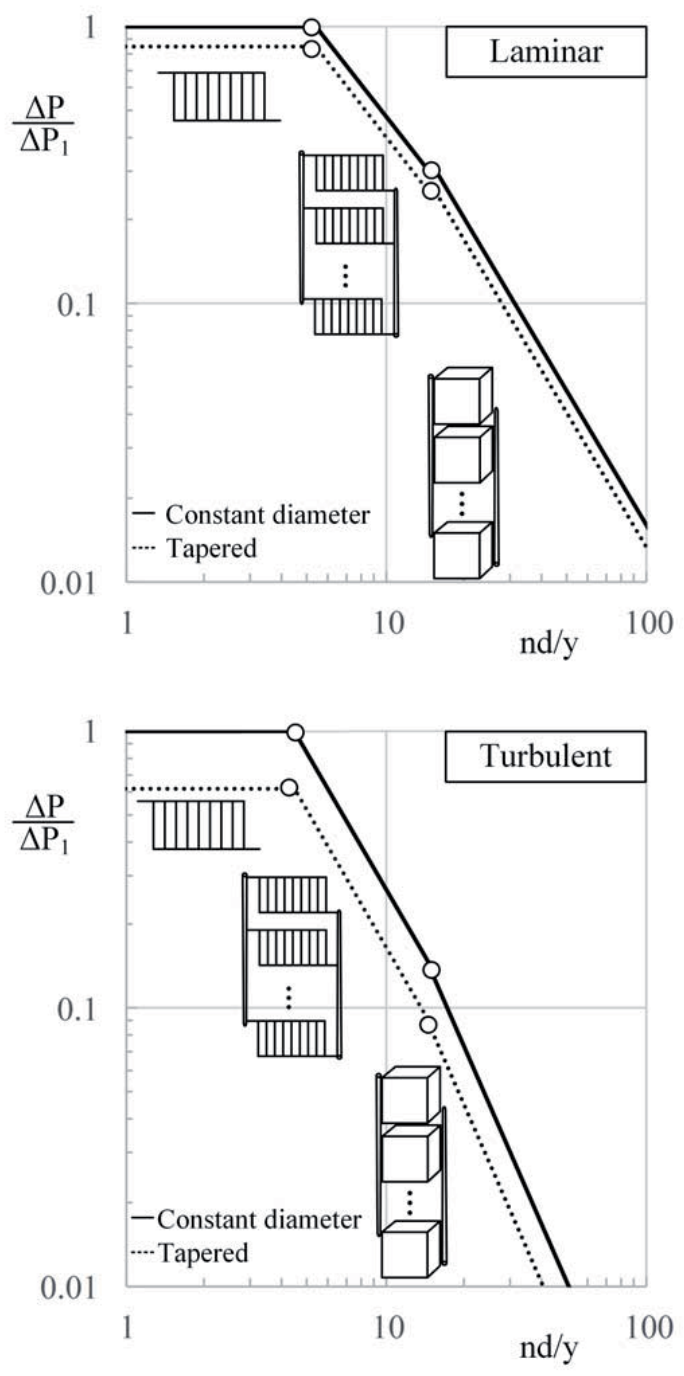

FIG. 7: The pressure drop of the designs of Figs. 2, 3, and 5 divided by the pressure drop of the design of Fig. 1 with laminar (top) and turbulent (bottom) flows

\section{CONCLUSIONS}

In this paper, we showed that the pressure drop of the designed porous material decreases with tapered ducts. The finite-size porous material with embedded vascular structure is bathed volumetrically by one single stream, which then leaves the structure as one stream through a collecting duct. Every elemental volume receives fluid as every cells receives blood in the veins of animals.

This paper shows how the ducts of a vascular structure can be tapered in order to decrease the pressure drop in laminar and turbulent flows. The volume ratio of the distributing ducts and their shapes are documented. Tapering the ducts decreases the pressure drop in laminar and turbulent flows, $16 \%$ and $38 \%$, respectively. The decrease in the pressure drop by tapering the ducts is the same in the first, second, and third constructs. Therefore, the pressure drop of the vascular design can be calculated for the ducts of constant diameter and then the merit can be calculated by using Eqs. (10) and (11).

This paper shows that the assumption of the ducts of constant diameter is a good approximation of the tapered ducts. However, the merit of $16 \%$ to $38 \%$ on the pressure drop relative to the flow regime means the decrease in the needed pumping power and the cost of pumping for the distribution.

\section{ACKNOWLEDGMENT}

This work was supported by the Republic of Turkey.

\section{REFERENCES}

Aragon, A. M., Saksena, R., Kozola, B. D., Geubelle, P. H., Christensen, K. T., and White, S. R., Multi-physics optimization of three-dimensional microvascular polymeric components, J. Comput. Phys., vol. 233, pp. 132-147, 2013.

Bejan, A. and Lorente, S., Design with Constructal Theory, Wiley, Hoboken, NJ, 2008.

Bejan, A. and Lorente, S., The constructal law of design and evolution in nature, Philos. Trans. R. Soc. B, vol. 365, pp. 1335-1347, 2010.

Bejan, A. and Lorente, S., Constructal law of design and evolution: Physics, biology, technology and society, J. Appl. Phys., vol. 113, p. 151301, 2013.

Bejan, A., Lorente, S., and Wang, K.-M., Networks of channels for self-healing composite materials, J. Appl. Phys., vol. 100, p. 033528, 2006.

Bejan, A. and Zane, J. P., Design in Nature: How the Constructal Law Governs Evolution in Biology, Physics, Technology and Social Organization, Doubleday, New York, 2012. 
Beyene, A. and Peffley, J., Constructal theory, adaptive motion, and their theoretical application to low-speed turbine design, J. Energy Eng., vol. 135, pp. 112-118, 2009.

Cetkin, E., Lorente, S., and Bejan, A., Natural constructal emergence of vascular design with turbulent flow, J. Appl. Phys., vol. 107, p. 114901, 2010.

Cetkin, E., Lorente, S., and Bejan, A., Hybrid grid and tree structures for cooling and mechanical strength, J. Appl. Phys., vol. 110, p. 064910, 2011.

Chen, Y. and Cheng, P., An experimental investigation on the thermal efficiency of fractal tree-like microchannel nets, Int. Commun. Heat Mass Transfer, vol. 32, pp. 931-938, 2005.

Cho, K.-H., Chang, W.-P., and Kim, M.-H., A numerical and experimental study to evaluate performance of vascularized cooling plates, Int. J. Heat Fluid Flow, vol. 32, pp. 11861198, 2011.

da Silva, A. K. and Bejan, A., Constructal multi-scale structure for maximal heat transfer density in natural convection, Int. J. Heat Fluid Flow, vol. 26, pp. 34-44, 2005.

Errera, M. R. and Bejan, A., Tree networks for flows in composite porous media, J. Porous Media, vol. 2, pp. 1-17, 1999.

Hamilton, A. R., Sottos, N. R., and White, S. R., Self-healing of internal damage in synthetic vascular materials, Adv. Mater., vol. 22, pp. 5159-5163, 2010.

Kim, S., Lorente, S., Bejan, A., Miller, W., and Morse, J., The emergence of vascular design in three dimensions, J. Appl. Phys., vol. 103, p. 123511, 2008.

Liu, H. and Li, P., Even distribution/dividing of single-phase fluids by symmetric bifurcation of flow channels, Int. J. Fluid Flow, vol. 40, pp. 165-179, 2013.

Lorenzini, G. and Rocha, L. A. O., Constructal design of T-Y assembly of fins for an optimized heat removal, Int. J. Heat Mass Transfer, vol. 52, pp. 1458-1463, 2009.

Lorente, S. and Bejan, A., Vascularized smart materials: Designed porous media for self-healing and self-cooling, $J$. Porous Media, vol. 12, pp. 1-18, 2009.

Miguel, A. F., Constructal pattern formation in stony corals, bacterial colonies and plant roots under different hydrodynamics conditions, J. Theor. Biol., vol. 242, pp. 954-961, 2006.

Miguel, A. F., Dendritic structures for fluid flow: laminar, turbulent and constructal design, J. Fluids Struct., vol. 26, pp. 330-335, 2010a.

Miguel, A. F., Fluid flow in tree-shaped constructal networks: Porosity, permeability and inertial parameter, Defect Diffusion Forum, vol. 297-301, pp. 408-412, 2010b.

Raja, V. A. P., Basak, T., and Das, S. K., Thermal performance of a multi-block heat exchanger designed on the basis of Bejan's constructal theory, Int. J. Heat Mass Transfer, vol. 51, pp. 3582-3594, 2008.

Reis, A. H., Constructal theory: From engineering to physics, and how flow systems develop shape and structure, Appl. Mech. Rev., vol. 59, pp. 269-282, 2006 a.

Reis, A. H., Constructal view of scaling laws of river basins, Geomorphology, vol. 78, pp. 201-206, 2006 b.

Reis, A. H. and Miguel, A. F., Constructal theory and flow architectures in living systems, Thermal Sci., vol. 10, pp. 57-64, 2006.

Reis, A. H., Miguel, A. F., and Aydin, M., Constructal theory of flow architecture of lungs, Med. Phys., vol. 31, pp. 11351140, 2004.

Rocha, L. A. O., Lorenzini, E., and Biserni, C., Geometric optimization of shapes on the basis of Bejan's Constructal theory, Int. Commun. Heat Mass Transfer, vol. 32, pp. 1281-1288, 2005.

Soghrati, S., Thakre, P. R., White, S. R., Sottos, N. R., and Geubelle, P. H., Computational modeling and design of actively-cooled microvascular materials, Int. J. Heat Mass Transfer, vol. 55, pp. 5309-5321, 2012.

Therriault, D., White, S. R., and Lewis, J. A., Chaotic mixing in three-dimensional microvascular networks fabricated by direct write assembly, Nat. Mater., vol. 2, pp. 265-271, 2003.

Tondeur, D. and Luo, L., Design and scaling laws of ramified fluid distributors by the constructal approach, Chem. Eng. Sci., vol. 59, pp. 1799-1813, 2004.

Wang, X.-Q., Mujumdar, A. S., and Yap, C., Numerical analysis of blockage and optimization of heat transfer performance of fractal-like microchannel nets, J. Electron. Packag., vol. 128, pp. 38-45, 2006.

Wechsatol, W., Ordonez, J. C., and Kosaraju, S., Constructal dendritic geometry and the existence of asymmetric bifurcations, J. Appl. Phys., vol. 100, p. 113514, 2006.

Wu, W., Chen, L., and Sun, F., Heat-conduction optimization based on constructal theory, Appl. Energy, vol. 84, pp. 3947, 2007a.

Wu, W., Chen, L., and Sun, F., On the "area to point" flow problem based on constructal theory, Energy Convers. Manage., vol. 48, pp. 101-105, 2007 b.

Xu, P., Yu, B., Qiu, S., and Cai, J., An analysis of the radial flow in the heterogeneous porous media based on fractal and constructal tree networks, Physica A, vol. 387, pp. 6471-6483, 2008.

Zhou, S., Chen, L., and Sun, F., Optimization of constructal volume-point conduction with variable cross section conducting path, Energy Convers. Manage., vol. 48, pp. 106-111, 2007. 